\title{
Suppression of Lipopolysaccharide-Induced Inflammatory and Oxidative Response by 5-Aminolevulinic Acid in RAW 264.7 Macrophages and Zebrafish Larvae
}

\author{
Seon Yeong $\mathrm{Ji}^{1,2, \dagger}$, Hee-Jae Cha ${ }^{3, \dagger}$, Ilandarage Menu Neelaka Molagoda ${ }^{4}$, Min Yeong $\mathrm{Kim}^{1,2}$, So Young $\mathrm{Kim}^{1,2}$, \\ Hyun Hwangbo ${ }^{1,2}$, Hyesook Lee ${ }^{1,2}$, Gi-Young Kim ${ }^{4}$, Do-Hyung Kim ${ }^{5}$, Jin Won Hyun ${ }^{6}$, Heui-Soo Kim ${ }^{7}$, \\ Suhkmann $\mathrm{Kim}^{8}$, Cheng-Yun $\mathrm{Jin}^{9}$ and Yung Hyun Choi ${ }^{1,2, *}$ \\ ${ }^{1}$ Anti-Aging Research Center, Dong-eui University, Busan 47340, \\ ${ }^{2}$ Department of Biochemistry, College of Korean Medicine, Dong-eui University, Busan 47227, \\ ${ }^{3}$ Department of Parasitology and Genetics, College of Medicine, Kosin University, Busan 49104, \\ ${ }^{4}$ Department of Marine Life Sciences, Jeju National University, Jeju 63243, \\ ${ }^{5}$ Department of Aquatic Life Medicine, Pukyong National University, Busan 48513, \\ ${ }^{6}$ Department of Biochemistry, College of Medicine, Jeju National University, Jeju 63243, \\ ${ }^{7}$ Department of Biological Sciences, Pusan National University, Busan 46241, \\ ${ }^{8}$ Department of Chemistry, Pusan National University, Busan 46241, Republic of Korea \\ ${ }^{9}$ School of Pharmaceutical Sciences, Zhengzhou University, Henan 450001, China
}

\begin{abstract}
In this study, we investigated the inhibitory effect of 5-aminolevulinic acid (ALA), a heme precursor, on inflammatory and oxidative stress activated by lipopolysaccharide (LPS) in RAW 264.7 macrophages by estimating nitric oxide (NO), prostaglandin E2 (PGE2), cytokines, and reactive oxygen species (ROS). We also evaluated the molecular mechanisms through analysis of the expression of their regulatory genes, and further evaluated the anti-inflammatory and antioxidant efficacy of ALA against LPS in the zebrafish model. Our results indicated that ALA treatment significantly attenuated the LPS-induced release of pro-inflammatory mediators including NO and PGE2, which was associated with decreased inducible NO synthase and cyclooxygenase-2 expression. ALA also inhibited the LPS-induced expression of pro-inflammatory cytokines, such as tumor necrosis factor (TNF)- $\alpha$, interleukin (IL)-1 $\beta$, and IL-6, reducing their extracellular secretion. Additionally, ALA abolished ROS generation, improved the mitochondrial mass, and enhanced the expression of heme oxygenase-1 (HO-1) and the activation of nuclear translocation of nuclear factor-E2-related factor 2 (Nrf2) in LPS-stimulated RAW 264.7 macrophages. However, zinc protoporphyrin, a specific inhibitor of $\mathrm{HO}-1$, reversed the ALA-mediated inhibition of pro-inflammatory cytokines production and activation of mitochondrial function in LPS-treated RAW 264.7 macrophages. Furthermore, ALA significantly abolished the expression of LPS-induced pro-inflammatory mediators and cytokines, and showed strong protective effects against NO and ROS production in zebrafish larvae. In conclusion, our findings suggest that ALA exerts LPS-induced anti-inflammatory and antioxidant effects by upregulating the Nrf2/HO-1 signaling pathway, and that ALA can be a potential functional agent to prevent inflammatory and oxidative damage.
\end{abstract}

Key Words: 5-Aminolevulinic acid, Inflammation, ROS, Nrf2/HO-1

\section{INTRODUCTION}

Inflammation is usually a protective immune response against a variety of toxic or irritating conditions, such as bacterial or viral infections, harmful stimuli, and cellular damage (Liu et al., 2018; Aksentijevich et al., 2020). A properly regu- lated inflammatory response helps the body resist the insults, but excessive or abnormal inflammation causes hyperactivity in the body and is harmful. Excessive inflammatory reactions have been reported as the leading cause of diseases such as diabetes, rheumatoid arthritis, atherosclerosis, chronic hepatitis, pulmonary fibrosis, degenerative diseases, and various

\section{Open Access https://doi.org/10.4062/biomolther.2021.030}

This is an Open Access article distributed under the terms of the Creative Commons Attribution Non-Commercial License (http://creativecommons.org/licenses/by-nc/4.0/) which permits unrestricted non-commercial use, distribution, and reproduction in any medium, provided the original work is properly cited.
Received Feb 5, 2021 Revised Mar 11, 2021 Accepted Mar 15, 2021 Published Online Apr 6, 2021

\section{*Corresponding Author}

E-mail: choiyh@deu.ac.kr

Tel: +82-51-890-3319, Fax: +82-51-890-3333

${ }^{\dagger}$ The first two authors contributed equally to this work. 
cancers (Liu et al., 2018; Aksentijevich et al., 2020). Among the cells involved in immune regulation, macrophages play an important role in the innate immune defense system. Lipopolysaccharide (LPS), a major component of gram-negative bacterial cell walls, is widely used in various assays to study interference in the inflammatory pathway. In LPS-stimulated macrophages, the production of pro-inflammatory mediators and cytokines is increased by activation of the toll-like receptor (TLR) 4-mediated nuclear factor-kappaB (NF-kB) signaling pathway (Doyle and O'Neill, 2006; Hernandez et al., 2019). Nitric oxide (NO) and prostaglandin $\mathrm{E}_{2}\left(\mathrm{PGE}_{2}\right)$ are representative pro-inflammatory mediators, and pro-inflammatory cytokines such as tumor necrosis factor (TNF)- $\alpha$, interleukin (IL)$1 \beta$, IL-6, and IL-12. Moreover, the expression of inducible NO synthase (iNOS) and cyclooxygenase-2 (COX-2), which are involved in the production of $\mathrm{NO}$ and $\mathrm{PGE}_{2}$, respectively, is positively correlated with the expression of pro-inflammatory cytokines (Soufli et al., 2016; Aleem and Tohid, 2018).

On the other hand, reactive oxygen species (ROS) and related species, which are required for proper physiological function, serve as important signaling molecules that are closely related to host defense responses. However, oxidative stress, characterized by the excessive production of ROS, contributes to the progression of the inflammatory response and diseases (Bjørn and Hasselbalch, 2015; Liu et al., 2018). LPS can induce and accelerate oxidative stress along with the inflammatory cascade. Upon the LPS stimulation of macrophages, the production of ROS is also increased, contributing to the manifestation of inflammation, and overproduced inflammatory factors may promote excessive ROS production (Mills and O'Neill 2016; Liu et al., 2018). Recently, zebrafish (Danio rerio), which has great advantages as an in vivo animal model, has been widely used as a powerful vertebrate animal model for the study of human diseases (Bailone et al., 2020). In particular, since LPS-stimulated zebrafish exhibits inflammatory and oxidative reactions similar to those of mammals, it is recognized as an optimal in vivo model for the analysis of the anti-inflammatory and antioxidant efficacy of various drugs (Forn-Cuní et al., 2019; Rodríguez-Ruiz et al., 2020). Currently, non-steroidal anti-inflammatory drugs are widely used to suppress inflammatory symptoms and relieve oxidative stress, but various side effects have been reported from long-term use (Utzeri and Usai, 2017; Ferrer et al., 2019). Therefore, research on reliable and effective alternative agents for the prevention and treatment of various diseases is urgently needed.

5-Aminolevulinic acid (ALA), the first compound produced by ALA synthase in the heme biosynthetic pathway, is detected in plants, bacteria, fungi, and animals, and is also found in natural foods such as fruits, vegetables, and fermented liquors (Ishizuka et al., 2011; Fujino et al., 2016). Accumulated studies have shown that ALA has a variety of pharmacological effects, including anti-fibrotic, cardioprotective, immune tolerance, anti-tumor, anti-inflammatory, and antioxidant effects (Sugiyama et al., 2018; Nakano et al., 2019; Uchida et al., 2019). ALA supplementation also promotes mitochondrial respiratory activity by upregulating cytochrome c oxidase IV activity and ATP production through increased heme production (Kwon et al., 2012; Sugiyama et al., 2018). In addition, the exogenous addition of ALA has been shown to induce heme oxygenase-1 (HO-1) expression with increased intracellular heme levels, thereby inhibiting oxidative stress and increasing anti-inflammatory responses (Zhao et al., 2016; Liu et al., 2019). HO-1 is a typical cytoprotective and inducible enzyme. It is one of the downstream phase II enzymes dependent upon transcription factor nuclear factor- $\mathrm{E}_{2}$-related factor 2 (Nrf2) (Loboda et al., 2016; Saha et al., 2020). HO-1 breaks down heme released from unstable heme proteins into beneficial by-products such as carbon monoxide, biliverdin, and free iron. Biliverdin is converted to bilirubin very quickly by biliverdin reductase, and free iron promotes ferritin synthesis (Ollinger et al., 2007; Vanella et al., 2016). In particular, Sugiyama et al. (2018) reported that ALA attenuated the LPS-induced upregulation of NO and some pro-inflammatory cytokines in RAW 264.7 macrophages, which was associated with the induction of $\mathrm{HO}-1$ expression. Their results well-support previous findings that ALA may be a promising anti-inflammatory and antioxidant agent. However, the correlation between HO-1 induction by ALA and anti-inflammatory efficacy is still not well-known. Therefore, in this study, we used LPS-stimulated mouse RAW 264.7 macrophages to revalidate the inhibitory effect of ALA on inflammatory and oxidative responses and investigated how increased HO-1 affected the anti-inflammatory efficacy of ALA. We also demonstrated the anti-inflammatory and antioxidant potential of ALA in zebrafish.

\section{MATERIALS AND METHODS}

\section{Cell culture}

The RAW 264.7 cell line (ATCC ${ }^{\circledR}$ TIB-71 ${ }^{\mathrm{TM}}$ ), derived from murine macrophages, was purchased from the American Type Culture Collection (Manassas, VA, USA). The cells were maintained in humidified air at $37^{\circ} \mathrm{C}$, and $5 \% \mathrm{CO}_{2}$ in Dulbecco's modified Eagle's medium (DMEM) containing $100 \mathrm{U} / \mathrm{mL}$ penicillin and streptomycin, and $10 \%$ fetal bovine serum. All materials required for the cell culture were purchased from WelGENE Inc (Daegu, Korea). ALA and LPS were purchased from Abcam, Inc. (Cambridge, UK) and Sigma-Aldrich Chemical Co (St. Louis, MO, USA), respectively. They were dissolved in dimethyl sulfoxide (DMSO, Sigma-Aldrich Chemical Co.) and distilled water to make the stock solutions. Each stock solution (ALA $1 \mathrm{mM}$, LPS $100 \mathrm{mg} / \mathrm{mL}$ ) was appropriately diluted in the complete culture medium and used to treat RAW 264.7 cells. The final concentration of DMSO in the culture medium was kept below $0.05 \%$, which has been shown to have no significant toxicity to RAW 264.7 cells.

\section{Cell viability assay}

The cytotoxicity of ALA against RAW 264.7 cells in the presence or absence of LPS was determined using the 3-(4,5-dimethylthiazol-2-yl)-2,5-diphenyltetrazolium bromide (MTT) reduction assay. In brief, the cells were incubated in 96-well plates for $24 \mathrm{~h}$ at a density of $1 \times 10^{4}$ cells, and then treated with different concentrations of ALA alone or pre-treated with the indicated concentrations of ALA for $1 \mathrm{~h}$ before $100 \mathrm{ng} / \mathrm{mL}$ LPS treatment for $24 \mathrm{~h}$. Then, the medium was removed, and MTT solution (0.5 $\mathrm{mg} / \mathrm{mL}$, Sigma-Aldrich Chemical Co.) was dispensed into each well and reacted at $37^{\circ} \mathrm{C}$ as previously described (Choi, 2021). After $3 \mathrm{~h}$, the supernatant was removed and DMSO was added to dissolve the blue formazan crystals for $10 \mathrm{~min}$. The absorbance per well was quantified at a wavelength of $540 \mathrm{~nm}$ using an enzyme-linked immunosorbent assay (ELISA) plate reader (Dynatech Laboratories, Chantilly, VA, USA). To observe cell morphology changes, the cell images were captured using an 
inverted-phase contrast microscope (Carl Zeiss, Oberkochen, Germany).

\section{Measurement of NO, $\mathrm{PGE}_{2}$, and cytokines}

RAW 264.7 cells were treated with various concentrations of ALA for $1 \mathrm{~h}$ and then stimulated with LPS for $24 \mathrm{~h}$. The NO level in the medium was evaluated by the amount of nitrite measured using the Griess reagent (Sigma-Aldrich Chemical Co.) as previously described (Chae, 2020). Briefly, $100 \mu \mathrm{L}$ of the cell-conditioned medium was mixed with the same amount of Griess reagent for $10 \mathrm{~min}$. The absorbance was measured at $540 \mathrm{~nm}$ using an ELISA reader and calculated by comparison to a sodium nitrite $\left(\mathrm{NaNO}_{2}\right)$ standard curve. To investigate the $\mathrm{PGE}_{2}$ and cytokine levels, the culture supernatants were collected and assayed using commercially available ELISA kits (R\&D Systems Inc., Minneapolis, MN, USA) according to the instructions from the manufacturer. The absorbance was measured at a wavelength of $450 \mathrm{~nm}$ using an ELISA reader as previously described (Chae, 2020).

\section{Reverse transcription-polymerase chain reaction (RT-PCR) assay}

Total RNA was isolated from the cells using TRIzol reagent (Invitrogen Life Technologies, Carlsbad, CA, USA), following the manufacturer's instructions, and quantified. The isolated total RNA $(1 \mu \mathrm{g})$ was used to synthesize cDNA using AccuPower $^{\circledR}$ RT PreMix (Bioneer, Daejeon, Korea) according to the manufacturer's instructions. The cDNA generated at room temperature (RT) was amplified using the One-Step RT-PCR PreMix Kit with selected primers (iNtRON Biotechnology Inc., Seongnam, Korea). The amplified DNA products were electrophoresed on $1.5 \%$ agarose gels and visualized after ethidium bromide (EtBr, Sigma-Aldrich Chemical Co.) staining as previously described (Kim et al., 2019). The PCR primers were as follows: iNOS forward, 5'-ATG TCC GAA GCAAAC ATC AC-3' and reverse, 5'-TAA TGT CCA GGA AGT AGG TG-3'; COX-2 forward, 5'-CAG CAA ATC CTT GCT GTT CC-3' and reverse, 5'-TGG GCA AAG AAT GCA AAC ATC-3'; TNF- $\alpha$ forward, 5'TCT CAT CAG TTC TAT GGC CC-3' and reverse, 5'-GGG AGT AGA CAA GGT ACA AC-3'; IL-1 $\beta$ forward, 5'-ATG GCA ACT GTT CCT GAA CTC AAC T-3' and reverse, 5'-TTT CCT TTC TTA GAT ATG GAC AGG AC-3'; IL-6 forward, 5'-GGA GGC TTAATT ACA CAT GTT-3' and reverse, 5'-TGA TTT CAA GAT GAA TTG GAT-3', and glyceraldehyde-3-phosphate dehydrogenase (GAPDH) forward, 5'-AGG CCG GTG CTG AGT ATG TC-3' and reverse, 5'-TGC CTG CTT CAC CAC CTT CT3'. The following PCR conditions were applied: GAPDH: 18 cycles of denaturation at $94^{\circ} \mathrm{C}$ for $30 \mathrm{~s}$, annealing at $57^{\circ} \mathrm{C}$ for $30 \mathrm{~s}$, and extension at $72^{\circ} \mathrm{C}$ for $30 \mathrm{~s}$; iNOS, COX-2, IL-1 $\beta$ and IL-6: 25 cycles of denaturation at $94^{\circ} \mathrm{C}$ for $30 \mathrm{~s}$, annealing at $52^{\circ} \mathrm{C}$ for $30 \mathrm{~s}$, and extension at $72^{\circ} \mathrm{C}$ for $30 \mathrm{~s}$. GAPDH was used as an internal control to evaluate relative expression of iNOS, COX-2, IL-1 $\beta$ and IL-6.

\section{Protein isolation and Western blot analysis}

To extract proteins, the cells were washed with cold phosphate-buffered saline (PBS) and lysed with lysis buffer, followed by centrifugation at $14,000 \mathrm{rpm}$ for $30 \mathrm{~min}$ at $4^{\circ} \mathrm{C}$ as previously described (Park et al., 2020). The concentration of the isolated protein was measured using the Bio-Rad protein assay kit obtained from Bio-Rad Laboratories (Hercules, CA, USA). Equal amounts of protein were separated by sodium
Table 1. List of antibodies used for western blot analysis in the present study

\begin{tabular}{llll}
\hline Antibody & \multicolumn{1}{c}{ Manufacturer } & Item no. & Dilution \\
\hline iNOS & BD Biosciences & 610328 & $1: 1,000$ \\
COX-2 & Cayman Chemical Company & 160126 & $1: 500$ \\
& $\quad$ (Ann Arbor, MI, USA) & & \\
TNF- $\alpha$ & Cell Signaling Technology, Inc. & 37075 & $1: 1,000$ \\
IL-1 $\beta$ & Santa Cruz Biotechnology, Inc. & sc-7884 & $1: 1,000$ \\
IL-6 & Santa Cruz Biotechnology, Inc. & sc-28343 & $1: 1,000$ \\
HO-1 & Merck Millipore (Burlington, MA, & 374090 & $1: 1,000$ \\
& USA) & & \\
Nrf2 & Santa Cruz Biotechnology, Inc. & sc-13032 & $1: 1,000$ \\
p-Nrf2 & Abcam, Inc. & ab76026 & $1: 1,000$ \\
$\beta-a c t i n$ & Santa Cruz Biotechnology, Inc. & sc-47778 & $1: 1,000$ \\
\hline
\end{tabular}

dodecyl sulfate-polyacrylamide gel electrophoresis. Proteins in the gel were subsequently transferred to polyvinylidene difluoride (PVDF) membranes (Schleicher and Schuell GmbH, Keene, NH, USA). The protein-transferred membranes were blocked with non-fat dry milk solution (5\%) at RT for $1 \mathrm{~h}$, and then reacted with primary antibodies (Table 1) overnight at $4^{\circ} \mathrm{C}$. The membranes were washed three times for $5 \mathrm{~min}$ with Tris-buffered saline $(0.1 \%$ Tween- 20$)$ and then incubated with secondary antibodies for $2 \mathrm{~h}$ at RT. The membranes were reacted with an enhanced chemiluminescent solution purchased from Amersham Corp. (Arlington Heights, IL, USA) and then exposed to X-ray film to visualize the corresponding proteins. Secondary antibodies for rabbit IgG (rabbit, 1:1,000, \#7074) and mouse lgG (mouse, 1:1,000, sc-516102) were obtained from Cell Signaling Technology, Inc. (Beverly, MA, USA) and Santa Cruz Biotechnology, Inc. (Dallas, TX, USA), respectively.

\section{Measurement of ROS levels}

ROS was measured using 5,6-carboxy-2',7'-dichlorofluorescein diacetate (DCF-DA, Sigma-Aldrich Chemical Co.). Briefly, RAW 264.7 cells were pre-treated with various concentrations of ALA for $1 \mathrm{~h}$ and then incubated for $1 \mathrm{~h}$ in the absence or presence of $100 \mathrm{ng} / \mathrm{mL}$ LPS. The cells were stained with $10 \mu \mathrm{M}$ DCF-DA for $15 \mathrm{~min}$ in the dark at $37^{\circ} \mathrm{C}$. The cells were then washed with $\mathrm{PBS}$ and immediately analyzed by flow cytometry (BD Biosciences, San Jose, CA, USA) as previously described (Hwangbo et al., 2020).

\section{Immunofluorescence for phosphorylated-Nrf2 (p-Nrf2)}

RAW 264.7 cells were seeded into 4 -well cell culture slides and stabilized for $24 \mathrm{~h}$. The cells were pre-treated with $1 \mathrm{mM}$ ALA for $1 \mathrm{~h}$ and then treated with or without $100 \mathrm{ng} / \mathrm{mL}$ LPS for $24 \mathrm{~h}$. After treatment, the cells were fixed with ice-cold methanol for 10 min and washed with PBS. Subsequently, the cells were blocked using $5 \%$ bovine serum albumin (BSA, Sigma-Aldrich Chemical Co.) with PBS-T (PBS containing $0.1 \%$ Triton $X$ ) for $1 \mathrm{~h}$ and then incubated with anti-p-Nrf2 (1:100 in 2.5\% BSA in PBS-T) at $4^{\circ} \mathrm{C}$ overnight. The cells were washed with PBS-T and incubated with the secondary antibody (goat anti-rabbit IgG cross-absorbed secondary antibody conjugated to Alexa Fluor 594, Thermo Fisher Scientific, Waltham, MA, USA) for 1 h. After washing with PBS, the cells were counterstained with 4',6-diamidino-2-phenylindole (DAPI, Sigma-Aldrich Chemi- 
cal Co.) for $20 \mathrm{~min}$. Cell fluorescence was observed using a fluorescence microscope (Carl Zeiss) at Core-Facility Center for Tissue Regeneration (Dong-eui University, Busan, Korea).

\section{Quantification of mitochondrial mass}

To measure the mitochondrial content, RAW 264.7 cells were incubated with or without $1 \mathrm{mM}$ ALA for $1 \mathrm{~h}$, followed by incubation with or without $100 \mathrm{ng} / \mathrm{mL}$ LPS for $24 \mathrm{~h}$. The cells were stained with $100 \mathrm{nM}$ MitoTracker ${ }^{\circledR}$ Red (Molecular Probes, Inc., Eugene, OR, USA) in culture media for 15 $\min$ at $37^{\circ} \mathrm{C}$. After staining, the excess dye was washed out three times with PBS. The MitoTracker ${ }^{\circledR}$ Red signals were detected by flow cytometry according to the manufacturer's instructions. To compare the mitochondrial mass through fluorescence microscopic observation, the cells were stained with $100 \mathrm{nM}$ MitoTracker ${ }^{\circledR}$ Red for $15 \mathrm{~min}$ at $37^{\circ} \mathrm{C}$. The nucleus was stained with DAPI solution for $10 \mathrm{~min}$ at $37^{\circ} \mathrm{C}$ and then fixed with $4 \%$ paraformaldehyde solution $(\mathrm{pH} \mathrm{7.4)}$ for $20 \mathrm{~min}$. The cells were washed with PBS and images were acquired using a fluorescence microscope.

\section{Zebrafish maintenance and LPS microinjection}

AB strain zebrafish, which as provided by Dr. C. H. Kang (Nakdong National Institute of Biological Resources, Sangju, Korea), as maintained at $28.5^{\circ} \mathrm{C}$ with a $14 / 10 \mathrm{~h}$ light/dark cycle according to the standard guidelines of the Animal Care and Use Committee of Jeju National University (Approval No.: 2019-0053, Jeju, Korea). Fertilized embryos were collected after natural spawning as previously described (Jeong et al., 2018) and cultured in $2 \mathrm{mg} / \mathrm{L}$ methylene blue containing E3 embryo media at $28.5^{\circ} \mathrm{C}$. Three days post-fertilized (dpf) zebrafish larvae were anesthetized using 0.04\% tricaine (Sigma-Aldrich Chemical Co.) and LPS $(0.5 \mathrm{mg} / \mathrm{mL}, 2 \mathrm{~nL}$ in each larva) was microinjected into the yolk using a Drummond NANOJECT III injector (Drummond Scientific, Broomall, PA, USA). The negative control group was injected with PBS. The larvae were washed three times after LPS microinjection and immediately placed in E3 media containing the indicated concentrations of ALA. Each group of larvae $(n=20)$ was cultured at $28.5^{\circ} \mathrm{C}$ for $24 \mathrm{~h}$.

\section{NO and ROS staining in zebrafish larvae}

The production of $\mathrm{NO}$ and ROS in zebrafish larvae was visualized using 4-amino-5-methylamino-2'7'-difluorofluorescein diacetate (DAF-FM-DA, Sigma-Aldrich Chemical Co.) and DCF-DA, respectively, $24 \mathrm{~h}$ after chemical treatment as previously described (Jeong et al., 2018). In brief, zebrafish embryos (4 dpf) were transferred to 24-well plates and incubated with $5 \mu \mathrm{M}$ DAF-FM-DA and $20 \mu \mathrm{M}$ DCF-DA for $30 \mathrm{~min}$ and visualized using the CELENA ${ }^{\circledR} S$ Digital Imaging System (Logos Biosystems, Anyang, Korea). Fluorescence intensities were calculated using ImageJ software (Wayne Rasband, National Institute of Health, Bethesda, MD, USA) and expressed as a percentage compared to the untreated control.

\section{Isolation of total zebrafish RNA and RT-PCR}

Total RNA was extracted from the larvae (20 larvae from each treatment) using the easy-BLUE TM Total RNA Extraction Kit (iNtRON Biotechnology, Daejeon, Korea) at $24 \mathrm{dpf}$. As mentioned above, total RNA was isolated to synthesize cDNA, and amplified using selected primers (Karunarathne et al., 2020): iNOS forward, 5'-GGA GAT GCA AGG TCA GCT
TC-3' and reverse, 5'-GGC AAA GCT CAG TGA CTT CC-3'; COX-2a forward, 5'-CCT GTT GTC AAG GTC CCA TT-3' and reverse, 5'-TCA GGG ATG AAC TGC TTC CT-3'; IL-6 forward, 5'-AGA CCG CTG CCT GTC TAA AA-3' and reverse, 5'-CCA TCT CTC CGT CTC TCA CC-3'; IL-12 forward, 5'- TCT AAC TTC AGC GCA GTG GA-3' and reverse, 5'- TGC GGT GGT GTA GTG AGT G-3'. TNF- $\alpha$ forward, 5'-TAG AAC AAC CCA GCA AAC-3' and reverse, 5'-ACC AGC GGT AAA GGC AAC3'; and $\beta$-actin forward, 5'-CGA GCG TGG CTA CAG CTT CA$3^{\prime}$ and anti-sense 5'-GAC CGT CAG GCA GCT CAT AG-3'. The following PCR conditions were applied for PCR amplification: iNOS, IL-6 and IL-12, 27 cycles of denaturation at $95^{\circ} \mathrm{C}$ for $45 \mathrm{~s}$, annealing at $58^{\circ} \mathrm{C}$ for $45 \mathrm{~s}$, and extended at $72^{\circ} \mathrm{C}$ for $1 \mathrm{~min}$; TNF- $\alpha$ and COX-2a, 32 cycles of denaturation at $95^{\circ} \mathrm{C}$ for $45 \mathrm{~s}$, annealing at $57^{\circ} \mathrm{C}$ for $45 \mathrm{~s}$, and extended at $72^{\circ} \mathrm{C}$ for $1 \mathrm{~min} ; \beta$-actin, 27 cycles of denaturation at $95^{\circ} \mathrm{C}$ for $45 \mathrm{~s}$, annealing at $61^{\circ} \mathrm{C}$ for $45 \mathrm{~s}$, and extended at $72^{\circ} \mathrm{C}$ for $1 \mathrm{~min}$. $\beta$-Actin was used as an internal control to evaluate relative expression of iNOS, COX-2, IL-6 and IL-12, TNF- $\alpha$. The amplified DNA product was subjected to electrophoresis on $1.5 \%$ agarose gels and stained with $\mathrm{EtBr}$.

\section{Statistical analysis}

The data were analyzed with GraphPad Prism software (GraphPad Software, Inc., La Jolla, CA, USA) using one-way analysis of variance (ANOVA) for multiple comparisons, followed by Tukey's post hoc test. All numerical data are presented as the mean \pm standard deviation (SD) of at least triplicate experiments. $p$-values of less than 0.05 were considered statistically significant.

\section{RESULTS}

\section{Effect of ALA on the proliferation of RAW 264.7 macrophages}

The cytotoxic effect of ALA on RAW 264.7 cells was determined by the MTT assay. As shown in Fig. 1A, at concentrations below $1 \mathrm{mM}$, ALA was not cytotoxic to RAW 264.7 cells, but significant cytotoxicity was observed in groups treated with $10 \mathrm{mM}$ or more in a concentration-dependent manner. Subsequent experiments did not show any adverse effect on cell viability when $1 \mathrm{mM}$ or less ALA was administered to $100 \mathrm{ng} / \mathrm{mL}$ LPS-treated RAW 264.7 cells (Fig. 1B). In addition, spindleshaped pseudopodia, a macrophage activation signal, were formed in LPS-treated RAW 264.7 cells, while the original round shape remained in the presence of ALA (Fig. 1C).

\section{Inhibition of LPS-induced NO and $\mathrm{PGE}_{2}$ production by ALA in RAW 264.7 macrophages}

To evaluate the anti-inflammatory effects of ALA, changes in the levels of released inflammatory mediators such as NO and $\mathrm{PGE}_{2}$ were detected in RAW 264.7 cells pre-treated with ALA for $1 \mathrm{~h}$ and then stimulated with LPS for $24 \mathrm{~h}$. As shown in Fig. 2A and 2B, LPS stimulation markedly increased the release of $\mathrm{NO}$ and $\mathrm{PGE}_{2}$ compared to the unstimulated control, but this increase was significantly reduced in ALA-pre-treated cells in a concentration-dependent manner. Next, we investigated whether ALA could inhibit the expression of iNOS and COX-2 by LPS. According to the RT-PCR and Western blot results, the mRNA and protein expression of iNOS and COX-2 increased by LPS was significantly suppressed in the pres- 
ence of ALA (Fig. 2C-2H).

\section{Inhibition of LPS-induced production and expression of pro-inflammatory cytokines by ALA in RAW 264.7 macrophages}

Next, we investigated the effect of ALA on the production
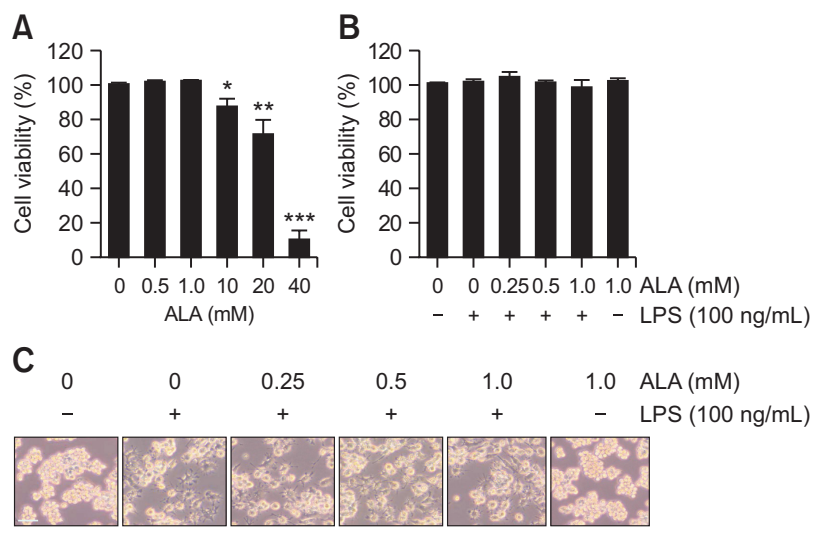

Fig. 1. Effect of ALA and LPS on the cell viability of RAW 264.7 macrophages. Cells were treated with various concentrations of ALA alone for $24 \mathrm{~h}(\mathrm{~A})$ or pre-treated with or without ALA for $1 \mathrm{~h}$ before $100 \mathrm{ng} / \mathrm{mL}$ LPS stimulation for $24 \mathrm{~h}(\mathrm{~B}, \mathrm{C})$. Cell viability was analyzed using the MTT assay. Each value indicates the mean \pm SD and is representative of three independent experiments. Significant differences among the groups were determined $\left({ }^{*} p<0.05\right.$, ${ }^{* *} p<0.01$ and ${ }^{* * *} p<0.001$, vs. LPS-unstimulated cells). (C) The morphology of the cells was visualized under an inverted-phase contrast microscope. Scale bar: $200 \mu \mathrm{m}$. and expression of pro-inflammatory cytokines increased by LPS treatment. Our results showed that the amount of proinflammatory cytokines, including TNF- $\alpha$, IL-1 1 , and IL-6, released into the culture supernatant after stimulation with LSP increased significantly. However, the enhanced production of these cytokines by LPS was significantly suppressed by ALA pretreatment, and this effect was dependent upon the ALA treatment concentration (Fig. 3A-3C). Subsequently, whether the inhibition of cytokine production by ALA in LPS-treated RAW 264.7 cells was associated with the decreased expression of these genes was also investigated. As shown in Fig. 3D-3G, LPS treatment significantly increased the expression of the three cytokine proteins, but their expression was reduced in cells pre-treated with ALA.

\section{Inhibition of LPS-induced ROS generation and HO-1 expression by ALA in RAW 264.7 macrophages}

Because oxidative stress also plays an important role in the inflammatory response, we investigated whether ALA could inhibit LPS-induced oxidative stress. The flow cytometry results using the DCF-DA probe showed that the increase in ROS content in RAW 264.7 cells treated with LPS was dramatically reduced by the addition of ALA in a concentrationdependent manner (Fig. 4A, 4B). To investigate whether the inhibitory effect of ALA on oxidative stress by LPS was related to the expression of $\mathrm{HO}-1$, the level of $\mathrm{HO}-1$ expression was analyzed in cells treated with LPS in the presence or absence of ALA. According to the results of the Western blot analysis, the expression of $\mathrm{HO}-1$ was increased by ALA treatment, which was associated with an increase in the expression of p-Nrf2, indicating that Nrf2 was activated, without changing the expression of its total protein (Fig. 4C, 4E). Although the
A
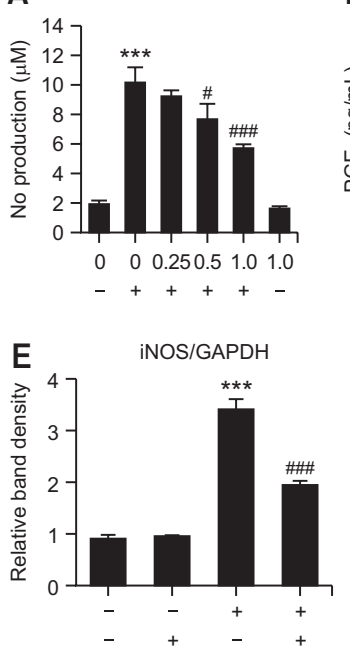

B

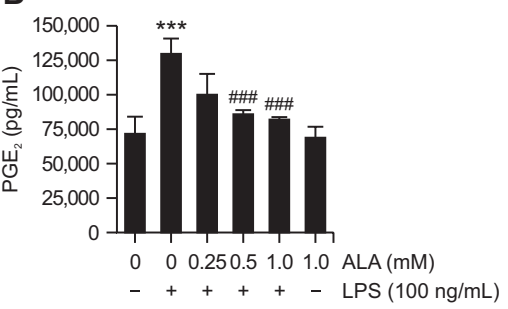

C

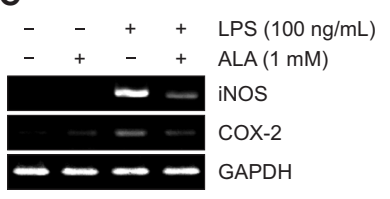

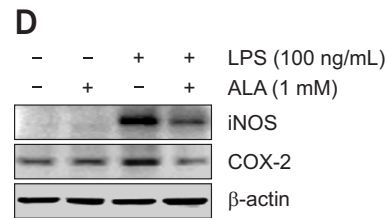
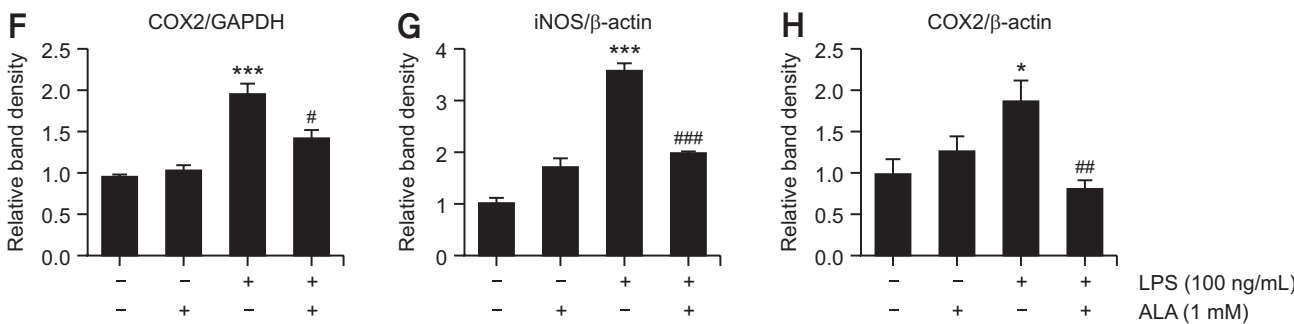

Fig. 2. Effect of ALA on the production and expression of pro-inflammatory mediators in LPS-stimulated RAW 264.7 macrophages. Cells were treated with the indicated concentrations of ALA for $1 \mathrm{~h}$ and then stimulated with $100 \mathrm{ng} / \mathrm{mL}$ LPS for $24 \mathrm{~h}$. (A) The NO concentration in the culture medium was determined by the Griess reaction. (B) The $\mathrm{PGE}_{2}$ concentration in the culture medium was determined using a commercial ELISA kit. (A, B) The absorbance was measured using a microplate reader. The error bars represent the mean $\pm S D$ of three independent experiments $\left({ }^{* * *} p<0.001\right.$, vs. LPS-unstimulated cells; ${ }^{\#} p<0.05$ and ${ }^{\# \#} p<0.001$, vs. LPS-stimulated cells). (C, D) After treatment, total RNA and protein were extracted from the cells. The expression levels of iNOS and COX-2 mRNA (C) and proteins (D) were measured by RT-PCR and Western blot analysis, respectively. GAPDH and $\beta$-actin and were used as internal controls for the RT-PCR and Western blot analyses, respectively. (E-H) Bands were quantified using ImageJ and normalized to GAPDH and $\beta$-actin, and the ratio was determined. Data are expressed as the mean \pm SD of three independent experiments $\left({ }^{*} p<0.05\right.$ and ${ }^{* * *} p<0.001$, vs. LPS-unstimulated cells; ${ }^{\#} p<0.05,{ }^{\#} p<0.01$ and ${ }^{\# \#} p<0.001$, vs. LPS-stimulated cells). 
A

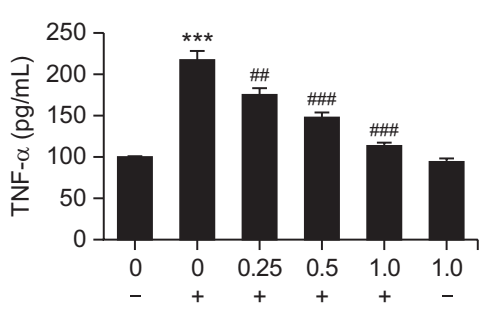

B

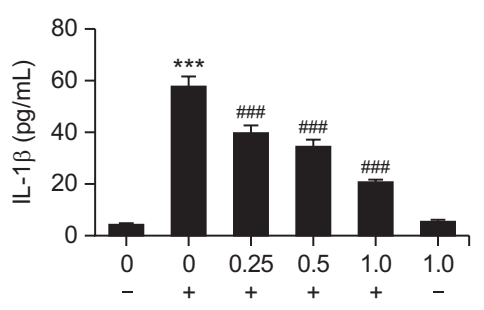

C

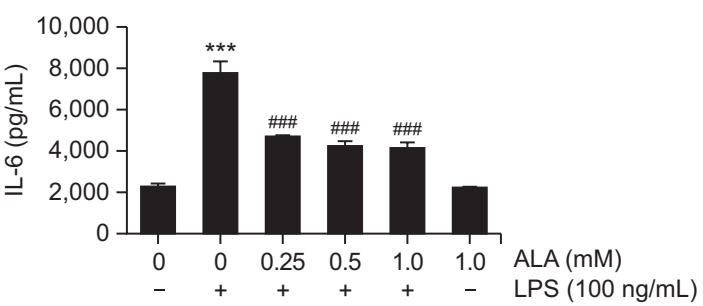

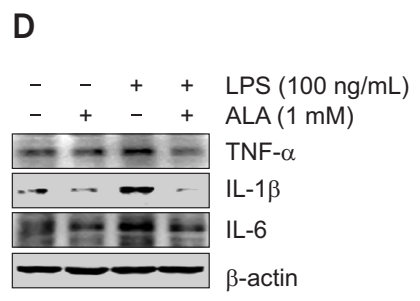
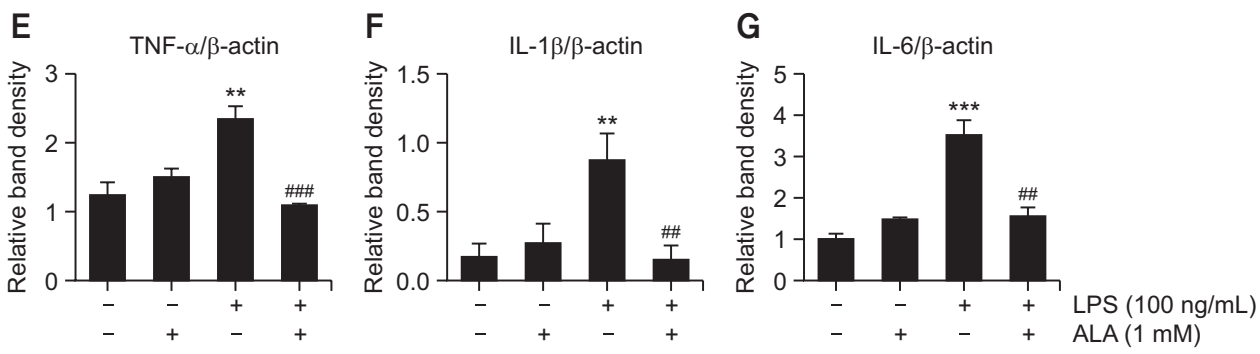

Fig. 3. Effect of ALA on the production and expression of pro-inflammatory cytokines in LPS-stimulated RAW 264.7 macrophages. Cells were treated with the indicated concentrations of ALA for $1 \mathrm{~h}$ and then stimulated with $100 \mathrm{ng} / \mathrm{mL}$ LPS for $24 \mathrm{~h}$. The concentrations of TNF- $\alpha$ $(A), I L-1 \beta(B)$, and IL-6 (C) in the culture medium were measured using commercial ELISA kits. The error bars represent the SD of three independent experiments $\left(^{* *} p<0.001\right.$, vs. LPS-unstimulated cells; ${ }^{\#} p<0.01$ and ${ }^{\# \#} p<0.001, v s$. LPS-stimulated cells). (D) After treatment, the total proteins were extracted from the cells. The expression levels of TNF- $\alpha$, IL- $1 \beta$, and IL- 6 proteins were measured by Western blot analysis. $\beta$-actin was used as an internal control for the Western blot analysis. (E-G) Bands were quantified using ImageJ, normalized to actin and ratios were determined. Data are expressed as the mean \pm SD. All experiments were repeated three times $\left({ }^{* *} p<0.01\right.$ and ${ }^{* * *} p<0.001$, vs. LPS-unstimulated cells; ${ }^{\#} p<0.01$ and ${ }^{\# \#} p<0.001$, vs. LPS-stimulated cells).

expression of $\mathrm{HO}-1$ and p-Nrf2 was slightly increased by treatment with LPS alone, the expression in cells co-treated with LPS and ALA was much higher that of cells treated with LPS and ALA alone (Fig. 4D, 4F). Consistent with the immunoblotting results, the increase in fluorescence intensity of p-Nrf2 observed in the nuclei of cells treated with LPS and ALA alone was markedly increased by co-treatment with LPS and ALA, as shown in Fig. 4G.

\section{Regulation of mitochondrial function by ALA in LPS- treated RAW 264.7 macrophages}

Next, the effect of ALA on the change in mitochondrial status was determined by MitoTracker ${ }^{\circledR}$ Red staining that detects mitochondrial levels and the status of fusion and division. As indicated by the flow cytometric results in Fig. 5A and 5B, LPS treatment alone slightly increased the frequency of MitoTracker ${ }^{\circledR}$ Red-positive cells, but in the presence of ALA, the frequency of these cells significantly increased. LPS slightly increased the fluorescence intensity of MitoTracker ${ }^{\circledR}$ Red when observed using a fluorescence microscope. However, the fluorescence intensity in cells co-treated with ALA was greatly increased (Fig. 5C), indicating that the mitochondrial mass was greatly improved by ALA.

\section{Effects of HO-1 inhibitor on ALA-induced anti- inflammatory and mitochondrial biogenesis-increasing effects in RAW 264.7 macrophages}

To further investigate the contribution of $\mathrm{HO}-1$ to the antiinflammatory effect of ALA, we used zinc protoporphyrin IX (ZnPP), a potent competitive inhibitor of $\mathrm{HO}-1$ inhibitor, to suppress HO-1 activity. To achieve this, we pre-incubated RAW 264.7 cells with ZnPP with or without ALA, followed by LPS, and found that ZnPP significantly counteracted the inhibitory effect of ALA on the increased release of pro-inflammatory cytokines such as TNF- $\alpha$, IL-1 $\beta$, and IL-6 by LPS (Fig. 6A-6C). We also found that ZnPP significantly reversed the effect of ALA on the increase in mitochondrial biogenesis in LPS-treated RAW 264.7 cells (Fig. 6D, 6E).

\section{Anti-inflammatory and antioxidant effects of ALA in LPS- treated zebrafish larvae}

As ALA downregulates inflammatory and oxidative responses in RAW 264.7 cells, we wondered if ALA had a similar effect in the in vivo model and demonstrated it using the zebrafish model. According to the results of DAF-FM-DA staining, LPS microinjection significantly increased NO generation. However, in the presence of ALA within a non-toxic range, the LPS-induced NO generation gradually decreased in a concentration-dependent manner (Fig. 7A, 7B). Consistent with this result, ALA concentration-dependently suppressed the increased expression of iNOS mRNA in LPS-microinjected zebrafish larvae (Fig. 7C, 7D). In addition, the increased expression of various pro-inflammatory cytokines such as TNF- $\alpha$, IL-6, and IL-12 as well as COX-2 by LPS was suppressed in zebrafish larvae cultured in ALA immersion conditions (Fig. 7C). Furthermore, we confirmed by DCF-DA staining that the increased ROS accumulation in LPS-microinjected zebrafish larvae was dose-dependently abrogated in the presence of ALA (Fig. 8).

\section{DISCUSSION}

The activation of macrophages serves to defend against 


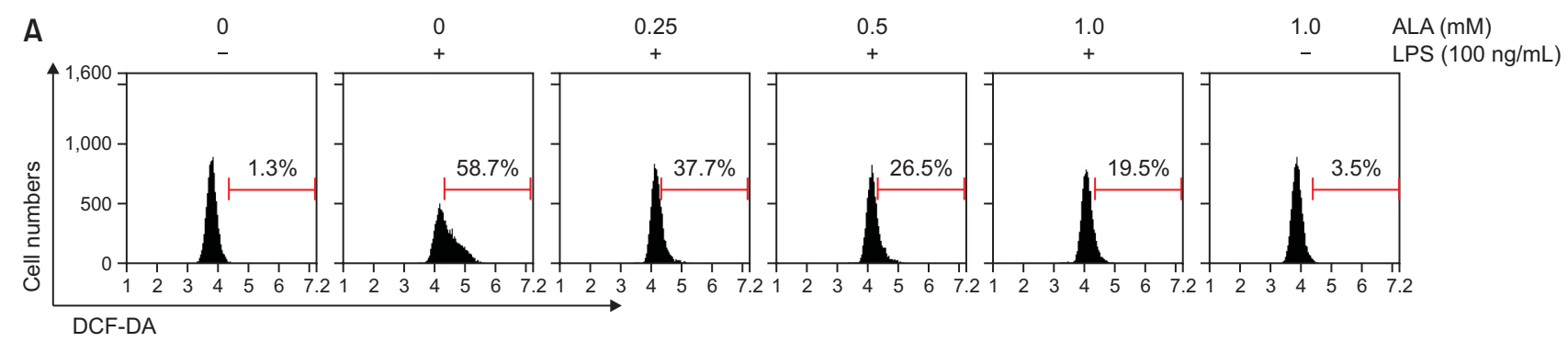

B

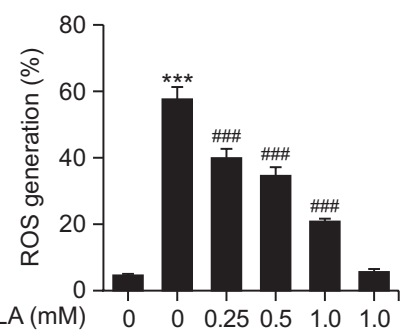

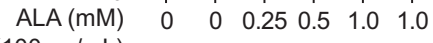

C

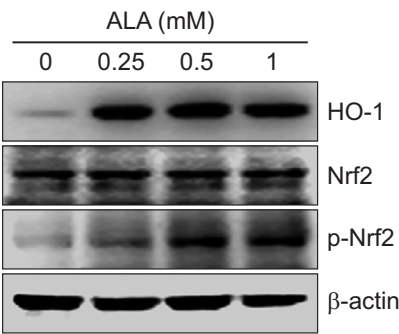

D

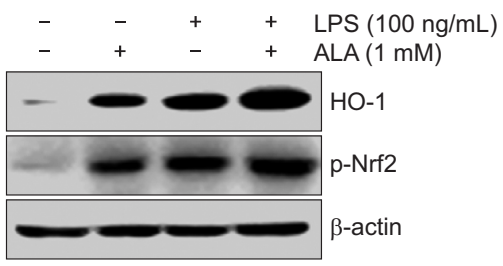
LPS $(100 \mathrm{ng} / \mathrm{mL})$

E

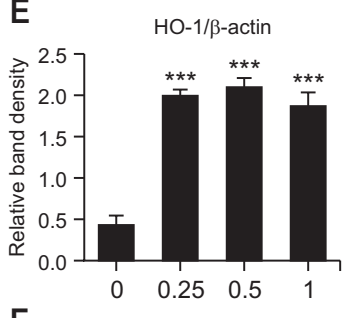

F

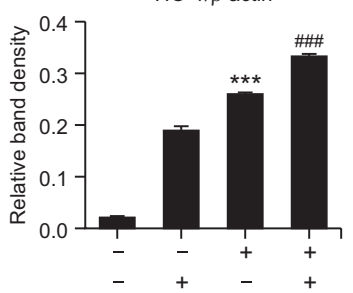

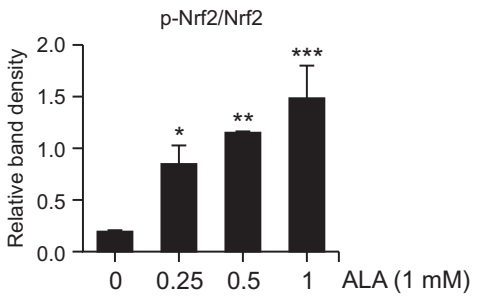

$\mathrm{p}-\mathrm{Nrf2} / \beta$-actin

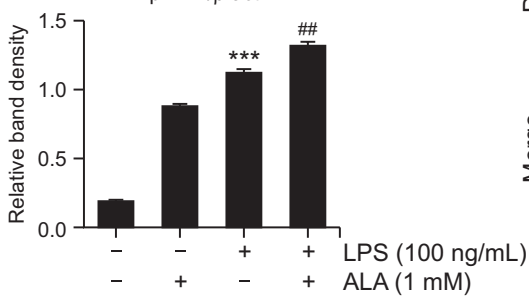

G

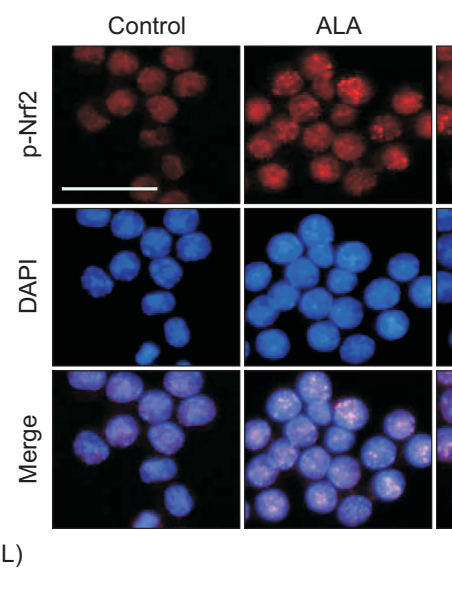

Fig. 4. Inhibition of ROS generation and activation of Nrf2 by ALA in LPS-stimulated RAW 264.7 macrophages. (A, B) Cells were pre-treated with the indicated concentrations of ALA for $1 \mathrm{~h}$ and then treated with $100 \mathrm{ng} / \mathrm{mL}$ LPS for $1 \mathrm{~h}$. (A) The DCF-DA-stained cells were collected, and then DCF fluorescence was analyzed by flow cytometry. (B) Data are given as the mean \pm SD of three independent experiments $\left({ }^{* * *} p<0.001\right.$, vs. LPS-unstimulated cells; ${ }^{\# \#} p<0.001$, vs. LPS-stimulated cells). (C-E) Cells were treated with the indicated concentrations of ALA alone for $24 \mathrm{~h}(\mathrm{C})$ or pre-treated with or without $1 \mathrm{mM}$ ALA for $1 \mathrm{~h}$ before $100 \mathrm{ng} / \mathrm{mL}$ LPS stimulation for $24 \mathrm{~h}$ (D, E). (C, D) The protein expression of Nrf2, p-Nrf2, and HO-1 was measured by Western blot analysis. $\beta$-actin was used as an internal control. (E, F) Bands were quantified using ImageJ and normalized to $\beta$-actin or Nrf2, and the ratio was determined. Data are expressed as the mean \pm SD of three independent experiments $\left({ }^{*} p<0.05,{ }^{* *} p<0.01\right.$ and ${ }^{* * *} p<0.001$, vs. LPS-unstimulated cells; ${ }^{\# \#} p<0.01$ and ${ }^{\# \#} p<0.001, v s$. LPS-stimulated cells). (G) The cells were subjected to immunofluorescence staining with p-Nrf2 antibody and representative fluorescence images were acquired using a fluorescence microscope. Red fluorescence indicates the localization of p-Nrf2 and blue fluorescence by DAPI staining allows visualization of the nuclei. Scale bar: $200 \mu \mathrm{m}$.

inflammation caused by external stimuli, but excessive inflammatory reactions damage tissues and contribute to the development and progression of diseases related to inflammation (Doyle and O'Neill, 2006; Hernandez et al., 2019). In addition, ROS generated from overactive macrophages induce oxidative stress and can serve as a secondary messenger that further amplifies the inflammatory cascade, and inflammationinducing factors are also involved in the production of ROS (Lee and Yang, 2012; Mills and O'Neill 2016; Liu et al., 2018).
In this study, to evaluate the anti-inflammatory efficacy of ALA, we first investigated its effect on the production of NO and $\mathrm{PGE}_{2}$, which are classified as pro-inflammatory mediators (Saini and Singh, 2019; Yao and Narumiya, 2019). Among them, NO, which is synthesized from L-arginine by NO synthase, plays a critical role in normal physiological conditions such as neurotransmission, vasodilation, and immune defense. However, excessive NO formation due to increased iNOS expression promotes the inflammatory response and in- 


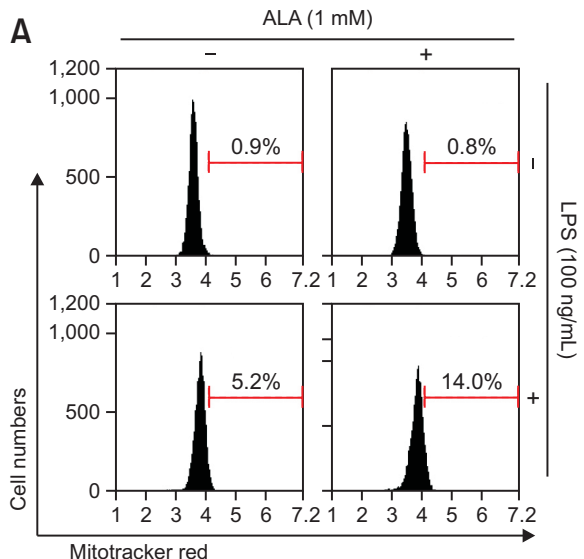

B

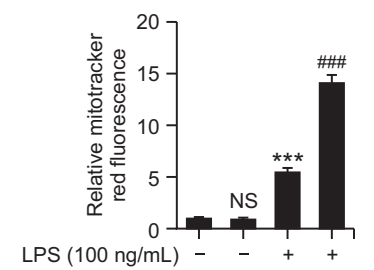

$\mathrm{ALA}(1 \mathrm{mM})-+-+$
C

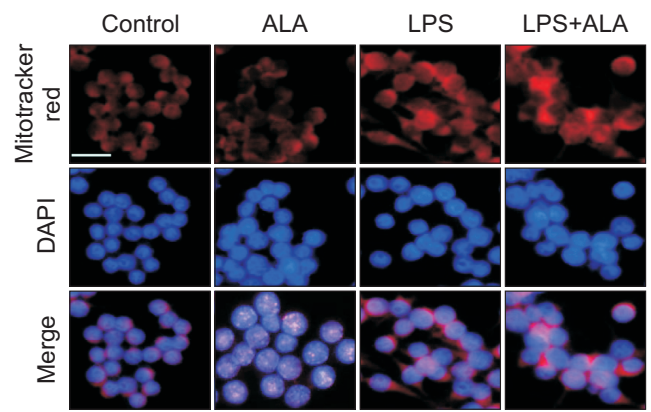

Fig. 5. Increase in mitochondrial mass by ALA in LPS-stimulated RAW 264.7 macrophages. Cells were pre-treated with $1.0 \mathrm{mM} A L A$ for $1 \mathrm{~h}$ and then treated with $100 \mathrm{ng} / \mathrm{mL}$ LPS for an additional $24 \mathrm{~h}$, followed by staining with MitoTracker ${ }^{\circledR}$ Red. (A) The cells were collected, and the total mitochondrial mass was analyzed by flow cytometry. (B) Data are given as the mean \pm SD of three independent experiments (NS, not significant; ${ }^{* * *} p<0.001$, vs. LPS-unstimulated cells; ${ }^{\# \#} p<0.001$, vs. LPS-stimulated cells). (C) The cells were subjected to immunofluorescence staining with Mitotracker ${ }^{\circledR}$ Red and representative fluorescence images were acquired using a fluorescence microscope. Red fluorescence indicates the localization of mitochondria and blue fluorescence by DAPI staining allows visualization of the nuclei. Scale bar: 200 $\mu \mathrm{m}$.

A

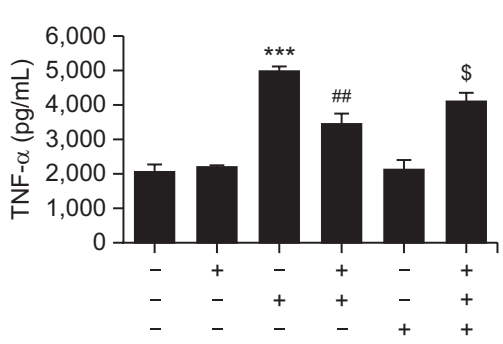

B

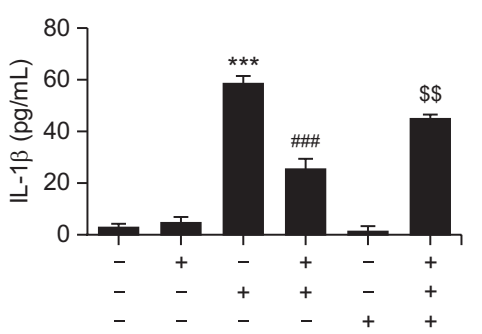

\section{C}

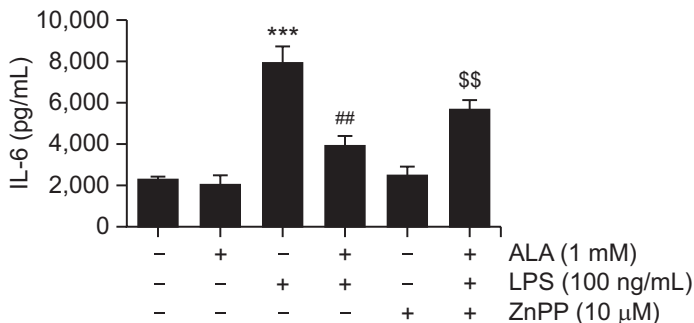

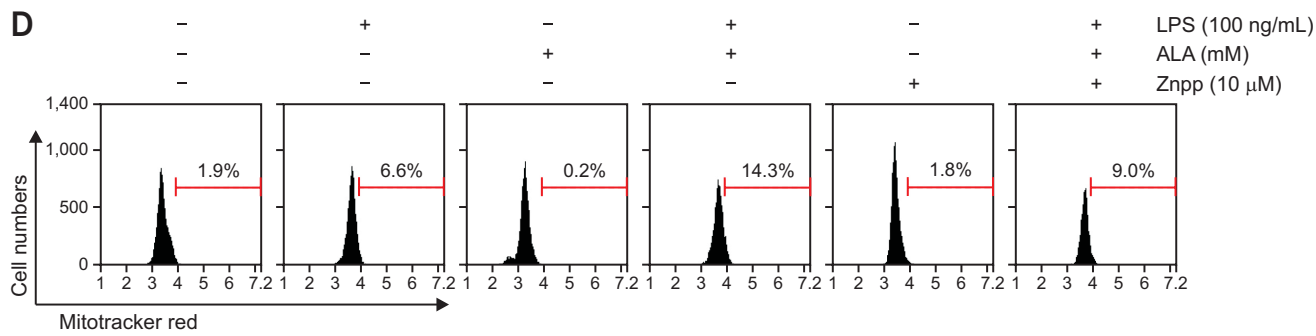

E

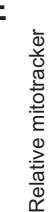

ALA $(1 \mathrm{mM})$ PS $(100 \mathrm{ng} / \mathrm{mL})--++-+$

Fig. 6. The role of Nrf2/HO-1 signaling in the anti-inflammatory efficacy of ALA on LPS-stimulated RAW 264.7 macrophages. Cells were pre-incubated with ZnPP at $10 \mu \mathrm{M}$ for $2 \mathrm{~h}$, followed by $1 \mathrm{~h}$ of incubation with $1.0 \mathrm{mM}$ ALA and exposure to $100 \mathrm{ng} / \mathrm{mL}$ LPS for $24 \mathrm{~h}$. (A-C) The concentrations of TNF- $\alpha(A), I L-1 \beta(B)$, and IL-6 (C) in the culture medium were measured using commercial ELISA kits. (D, E) The cells were collected, stained with MitoTracker ${ }^{\circledR}$ Red, and the total mitochondrial mass was analyzed by flow cytometry. Data are given as the mean \pm SD of three independent experiments $\left({ }^{* * *} p<0.001\right.$, vs. LPS-unstimulated cells; ${ }^{\#} p<0.01$ and ${ }^{\# \#} p<0.001$, vs. LPS-stimulated cells; ${ }^{\$} p<0.05,{ }^{\$ \$} p<0.01$ and ${ }^{\$ \$} p<0.001, v s$. ALA and LPS-stimulated cells).

creases oxidative stress and tissue damage (Saini and Singh, 2019; Yao and Narumiya, 2019). COX enzymes catalyze the conversion of arachidonic acid to prostaglandins, including $\mathrm{PGE}_{2}$, a group of hormone-like substances that participate in various body functions (Soufli et al., 2016; Aleem and Tohid, 2018). However, excessive $\mathrm{PGE}_{2}$ production, promoted by the increased activity of COX-2 following various inflammatory stimuli, plays an important role as an inflammatory mediator (Saini and Singh, 2019; Yao and Narumiya, 2019). Therefore, inhibitors of the excessive production of these inflammatory mediators can be regarded as therapeutic agents against inflammation-related diseases. Our data indicated that the upgraduated secretion of $\mathrm{NO}$ and $\mathrm{PGE}_{2}$ by LPS in RAW 264.7 macrophages was progressively inhibited at increasing concentrations of ALA, which was associated with inhibition of the expression of iNOS and COX-2 mRNA and protein, and support the results of previous studies by Nakano et al. (2019). These data demonstrated that the anti-inflammatory effect of 
A

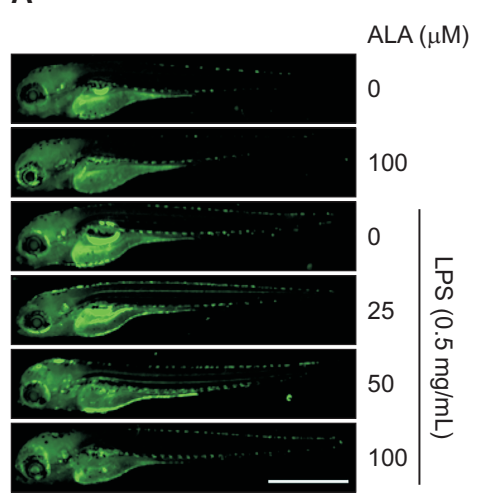

B

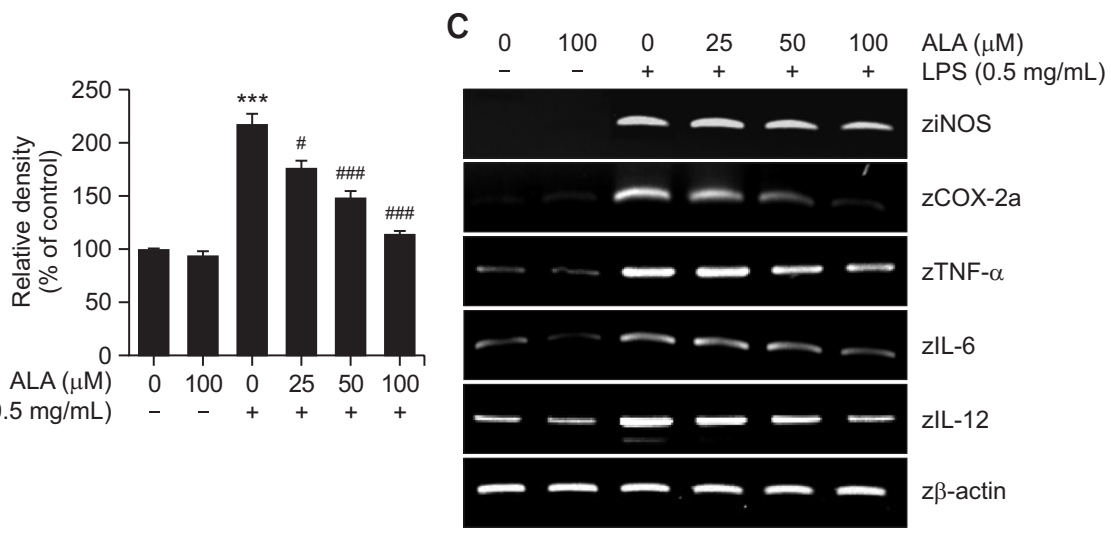

D

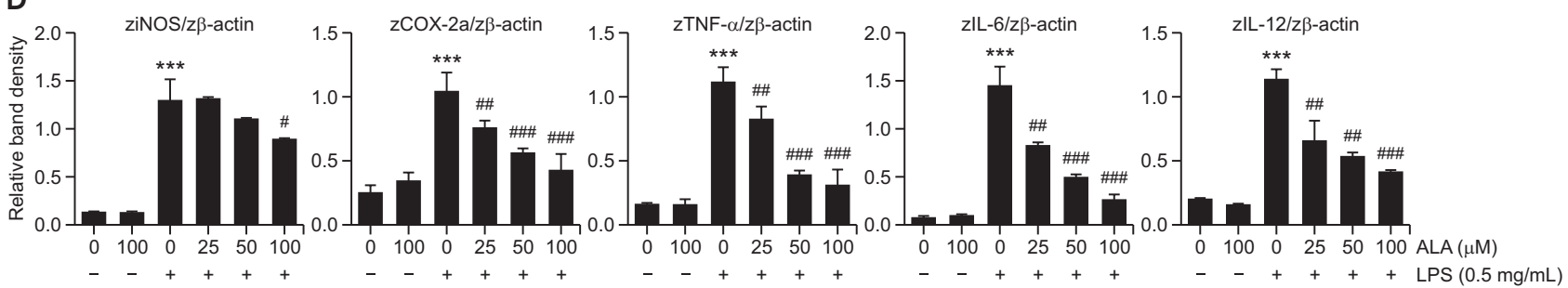

Fig. 7. Inhibition of LPS-induced inflammatory response by ALA in zebrafish larvae. Zebrafish at 3 dpf were microinjected with $2 \mathrm{~nL}$ of 0.5 $\mathrm{mg} / \mathrm{mL}$ LPS and placed in E3 media containing the indicated concentrations of ALA for $24 \mathrm{~h}$. (A) The larvae were incubated with $5 \mu$ M DAFFM-DA for NO detection and visualized using the CELENA ${ }^{\circledR} S$ Digital Imaging System. Scale bar: 1,000 $\mu \mathrm{m}$. (B) Relative fluorescence intensities were calculated and expressed compared to the untreated control. Each value indicates the mean \pm SD and is representative of three independent experiments with 20 fish for each group. Significant differences among the groups were determined ${ }^{* * *} p<0.001, v s$. LPS-unstimulated larvae; ${ }^{*} p<0.0$ and ${ }^{\# \#} p<0.001$, vs. LPS-stimulated larvae). (C) Total mRNA was isolated and RT-PCR was performed to analyze the gene expression of ziNOS, zCOX-2a, zIL-6, zIL-12, and zTNF- $\alpha$. z $\beta$-actin was used as the internal control. (D) Bands were quantified using ImageJ, normalized to $z \beta$-actin and ratios were determined. Data are expressed as the mean \pm SD. All experiments were repeated three times $\left({ }^{* * *} p<0.001\right.$, vs. LPS-unstimulated cells; ${ }^{\#} p<0.05,{ }^{\#} p<0.01$ and ${ }^{\# \#} p<0.001$, vs. LPS-stimulated cells).

A

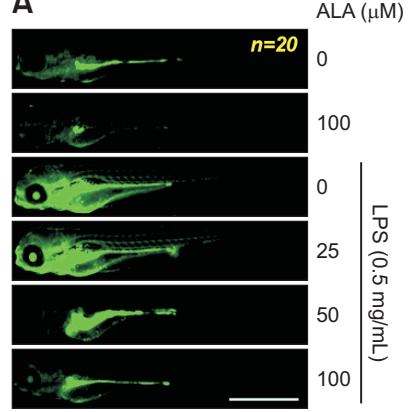

B

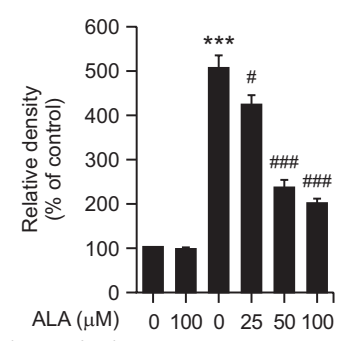

LPS $(0.5 \mathrm{mg} / \mathrm{mL})--++++$

Fig. 8. Inhibition of LPS-induced ROS generation by ALA in zebrafish larvae. Zebrafish at $3 \mathrm{dpf}$ as microinjected with $2 \mathrm{~nL}$ of 0.5 $\mathrm{mg} / \mathrm{mL}$ LPS and placed in E3 media containing the indicated concentrations of ALA for $24 \mathrm{~h}$. (A) The larvae were incubated with 20 $\mu \mathrm{M}$ DCF-DA for ROS detection and visualized using the CELENA ${ }^{\circledR}$ $S$ Digital Imaging System. Scale bar: $1,000 \mu \mathrm{m}$. (B) Relative fluorescence intensities were calculated and expressed compared to the untreated control. Each value indicates the mean $\pm S D$ and is representative of three independent experiments with 20 fish for each group. Significant differences among the groups were determined $\left({ }^{* * *} p<0.001\right.$, vs. LPS-unstimulated larvae; ${ }^{*} p<0.05$ and $p<0.001$, vs. LPS-stimulated larvae).

ALA was due to the reduced expression of iNOS and COX-2, which are involved in $\mathrm{NO}$ and $\mathrm{PGE}_{2}$ production.

During the inflammatory response, macrophages secrete multiple pro-inflammatory cytokines that are involved in various signaling pathways producing autocrine and/or paracrine effects (Wang et al., 2017; Hu et al., 2020; Zhang et al., 2020). All of these are essential components for the initiation and improvement of the inflammatory response, and their expression is increased by the LPS stimulation of macrophages (Soufli et al., 2016; Aleem and Tohid, 2018). They can also accelerate the inflammatory response by activating or increasing the expression of pro-inflammatory mediators as well as other pro-inflammatory cytokines (Soufli et al., 2016; Zhang et al., 2020). Although the expression of pro-inflammatory cytokines is tightly controlled by transcriptional and post-transcriptional mechanisms, they may have similar or even the same functional activity (Popa et al., 2007; Hu et al., 2020). Therefore, the level of pro-inflammatory cytokines has been applied as an indicator to evaluate anti-inflammatory efficacy in macrophages. In the current study, ALA reduced the production of TNF- $\alpha$, IL-1 $\beta$, and IL-6 in LPS-stimulated RAW 264.7 macrophages by suppressing their expression. Consistent with our results, Sugiyama et al. (2018) also reported similar effects in RAW 264.7 macrophages, and these results support the anti-inflammatory efficacy of ALA found in several experimental models (Liu et al., 2018; Nakano et al., 2019; Uchida et al, 2019).

Meanwhile, endogenous free radicals like ROS play an im- 
portant role in host defense. However, excess ROS can cause oxidative damage to cellular macromolecules, and has been shown to play a key role in initiating and promoting inflammation-related diseases by upregulating the production of inflammatory mediators and cytokines (Bjørn and Hasselbalch, 2015; Liu et al., 2018). ROS also contribute to the activation of macrophages, and ROS generation is enhanced in overactive macrophages (Mills and O'Neill 2016; Liu et al., 2018). Because mitochondria are the main intracellular organs responsible for ROS production and are susceptible to attack by ROS, oxidative stress is closely related to changes in mitochondrial function (Singh et al., 2019; Kowalska et al., 2020). For example, LPS increases the production of superoxide and hydrogen peroxide by reducing complex I activity, the main source of mitochondrial ROS (Murphy, 2009; Koopman et al., 2010). These observations support that ROS, along with the evaluation of mitochondrial function, are an important indicator of the mechanism of inflammation regulation. According to our results, ALA strongly inhibited LPS-induced ROS formation in RAW 264.7 macrophages. And, as in previous studies (Afrin et al., 2018; Yu et al., 2020), the mitochondrial mass was slightly increased in LPS-treated cells. However, compared to cells treated with only LPS, the combined treatment with ALA and LPS increased the mitochondrial mass by more than 3.5 times. Although the increase in mitochondrial mass is believed to have contributed to the improvement in mitochondrial function against oxidative stress caused by the inflammatory response (Mills and O'Neill 2016; Skuratovskaia et al., 2020), further studies on related mechanisms, including energy metabolism are needed. Nevertheless, our results are in good agreement with the results of previous studies showing that various natural products or drugs with anti-inflammatory effects improved mitochondrial function in LPS-activated macrophages (Afrin et al., 2018; Hong et al., 2020; Yu et al., 2020).

Certain antioxidant signaling pathways negatively modulate excessive inflammatory responses to maintain homeostasis in the body (He et al., 2017; Saha et al., 2020). Our results mentioned above indicated that ALA could increase the activity of the intracellular antioxidant enzyme system to reduce oxidative damage. ALA is a potent HO-1 inducer (Zhao et al., 2016; Liu et al., 2019) and this effect was confirmed in this study. Accumulated evidence indicates that $\mathrm{HO}-1$, along with its byproducts, can stimulate the production of anti-inflammatory cytokines, while inhibiting the production of pro-inflammatory mediators and cytokines (Choo et al., 2015; Saha et al., 2020). Nrf-2 is a major transcription factor that maintains cellular homeostasis associated with inflammation and oxidative stress by activating detoxifying genes, including $\mathrm{HO}-1$. For $\mathrm{Nrf}-2$ present in the cytoplasm to act as a transcription factor, it must be liberated from Kelch-like $\mathrm{ECH}$-associated protein 1 , a negative regulator of Nrf2, and phosphorylated before translocation to the nucleus (Loboda et al., 2016; Saha et al., 2020). Interestingly, the improvement in mitochondrial biogenesis by the activation of $\mathrm{HO}-1$ was found to be essential for blocking inflammatory and oxidative reactions by LPS in RAW 264.7 macrophages (Shi et al., 2019; Hong et al., 2020). In this study, ALA increased LPS-induced HO-1 protein levels, and the degree of phosphorylation of Nrf-2 was also markedly increased in cells co-treated with ALA and LPS, indicating that the activity of Nrf-2 as a transcription factor was improved. Along with this result, the expression of p-Nrf2 was observed only in the nucleus, and the fluorescence intensity of p-Nrf2 in each experimental group was consistent with the immunoblotting results. Therefore, the present results suggest that ALA increased the expression of $\mathrm{HO}-1$ by further promoting the phosphorylation of Nrf2 and nuclear translocation in the presence of LPS, and support the previous results that the increased expression of HO-1 by ALA may be Nrf2-dependent (Loboda et al., 2016; Saha et al., 2020). Moreover, ZnPP, an inhibitor of HO-1 activity, counteracted the inhibitory effects of ALA on LPS-induced pro-inflammatory cytokine production and increase in mitochondrial mass. These observations indicate that the anti-inflammatory and antioxidant effects of ALA on LPS stimulation are, at least, related to the activation of the Nrf2/HO-1 axis in RAW 264.7 macrophages. Since in vivo experiments can provide a better understanding of efficacy assessment at the organism level, the anti-inflammatory and antioxidant potential of ALA identified in macrophages was further confirmed in the zebrafish model. The present results showed the ability of ALA to protect inflammatory and oxidative reactions in the LPS-microinjected zebrafish larvae model by reducing $\mathrm{NO}$ and ROS generation. ALA was also able to inhibit the LPS-induced expression of pro-inflammatory enzymes and cytokines in zebrafish larvae, suggesting that ALA contributes significantly to attenuating the inflammatory response even in vivo. Although these results support previous results using various in vitro models (Zhao et al., 2016; Liu et al., 2019), additional mechanistic studies are needed to interpret the mechanisms related to the anti-inflammatory and antioxidant efficacy of ALA.

In summary, the current study showed that ALA could inhibit LPS-induced inflammatory and oxidative responses in RAW 264.7 macrophages and zebrafish larvae, which was evidenced by the reduced release of pro-inflammatory mediators and cytokines and the inhibition of ROS accumulation. ALA also increased mitochondrial mass and Nrf2-mediated HO-1 expression in the presence of LPS. However, when HO-1 activity was artificially blocked, the beneficial effects of ALA were negated. However, further studies are needed to determine the relationship between the $\mathrm{Nr} 2 / \mathrm{HO}-1$ signaling pathway, mitochondrial biogenesis, and other intracellular signaling pathways that may be involved in the beneficial efficacy of ALA.

\section{ACKNOWLEDGMENTS}

This research was a part of the project titled 'Omics based on fishery disease control technology development and industrialization (20150242)' funded by the Ministry of Oceans and Fisheries, Korea.

\section{REFERENCES}

Afrin, S., Gasparrini, M., Forbes-Hernández, T. Y., Cianciosi, D., Reboredo-Rodriguez, P., Manna, P. P., Battino, M. and Giampieri, F. (2018) Protective effects of Manuka honey on LPS-treated RAW 264.7 macrophages. Part 1: Enhancement of cellular viability, regulation of cellular apoptosis and improvement of mitochondrial functionality. Food Chem. Toxicol. 121, 203-213.

Aksentijevich, M., Lateef, S. S., Anzenberg, P., Dey, A. K. and Mehta, N. N. (2020) Chronic inflammation, cardiometabolic diseases and effects of treatment: psoriasis as a human model. Trends Cardiovasc. Med. 30, 472-478.

Aleem, D. and Tohid, H. (2018) Pro-inflammatory cytokines, biomark- 
ers, genetics and the immune system: a mechanistic approach of depression and psoriasis. Rev. Colomb. Psiquiatr. 47, 177-186.

Bailone, R. L., Fukushima, H. C. S., Ventura Fernandes, B. H., De Aguiar, L. K., Corrêa, T., Janke, H., Grejo Setti, P., Roça, R. O. and Borra, R. C. (2020) Zebrafish as an alternative animal model in human and animal vaccination research. Lab. Anim. Res. 36, 13.

Bjørn, M. E. and Hasselbalch, H. C. (2015) The role of reactive oxygen species in myelofibrosis and related neoplasms. Mediators Inflamm. 2015, 648090.

Chae, B. S. (2020) Effect of low-dose corticosterone pretreatment on the production of inflammatory mediators in super-low-dose LPSprimed immune cells. Toxicol. Res. 37, 47-57.

Choi, Y. H. (2021) Trans-cinnamaldehyde protects C2C12 myoblasts from DNA damage, mitochondrial dysfunction and apoptosis caused by oxidative stress through inhibiting ROS production. Genes Genomics 43, 303-312.

Choo, Y. Y., Lee, S., Nguyen, P. H., Lee, W., Woo, M. H., Min, B. S. and Lee, J. H. (2015) Caffeoylglycolic acid methyl ester, a major constituent of sorghum, exhibits anti-inflammatory activity via the Nrf2/heme oxygenase-1 pathway. RSC Adv. 5, 17786-17796.

Doyle, S. L. and O'Neill, L. A. (2006) Toll-like receptors: from the discovery of NFkappaB to new insights into transcriptional regulations in innate immunity. Biochem. Pharmacol. 72, 1102-1113.

Ferrer, M. D., Busquets-Cortés, C., Capó, X., Tejada, S., Tur, J. A., Pons, A. and Sureda, A. (2019) Cyclooxygenase-2 inhibitors as a therapeutic target in inflammatory diseases. Curr. Med. Chem. 26, 3225-3241.

Forn-Cuní, G., Meijer, A. H. and Varela, M. (2019) Zebrafish in inflammasome research. Cells 8, 901.

Fujino, M., Nishio, Y., Ito, H., Tanaka, T. and Li, X. K. (2016) 5-Aminolevulinic acid regulates the inflammatory response and alloimmune reaction. Int. Immunopharmacol. 37, 71-78.

He, L., He, T., Farrar, S., Ji, L., Liu, T. and Ma, X. (2017) Antioxidants maintain cellular redox homeostasis by elimination of reactive oxygen species. Cell. Physiol. Biochem. 44, 532-553.

Hernandez, A., Patil, N. K., Stothers, C. L., Luan, L., McBride, M. A., Owen, A. M., Burelbach, K. R., Williams, D. L., Sherwood, E. R. and Bohannon, J. K. (2019) Immunobiology and application of toll-like receptor 4 agonists to augment host resistance to infection. Pharmacol. Res. 150, 104502.

Hong, J. Y., Kim, H., Jeon, W. J., Baek, S. and Ha, I. H. (2020) Antioxidative effects of Thymus quinquecostatus CELAK through mitochondrial biogenesis improvement in RAW 264.7 macrophages. Antioxidants (Basel) 9, 548.

Hu, F., Lou, N., Jiao, J., Guo, F., Xiang, H. and Shang, D. (2020) Macrophages in pancreatitis: mechanisms and therapeutic potential. Biomed. Pharmacother. 131, 110693.

Hwangbo, H., Kim, S. Y., Lee, H., Park, S. H., Hong, S. H., Park, C. Kim, G. Y., Leem, S. H., Hyun, J. W., Cheong, J. and Choi, Y. H. (2020) Auranofin enhances sulforaphane-mediated apoptosis in hepatocellular carcinoma Hep3B cells through inactivation of the PI3K/Akt signaling pathway. Biomol. Ther. (Seoul) 28, 443-455.

Ishizuka, M., Abe, F., Sano, Y., Takahashi, K., Inoue, K., Nakajima, M., Kohda, T., Komatsu, N., Ogura, S. and Tanaka, T. (2011) Novel development of 5 -aminolevurinic acid $(A L A)$ in cancer diagnoses and therapy. Int. Immunopharmacol. 11, 358-365.

Jeong, J. W., Cha, H. J., Han, M. H., Hwang, S. J., Lee, D. S., Yoo, J. S., Choi, I. W., Kim, S., Kim, H. S., Kim, G. Y., Hong, S. H., Park, C., Lee, H. J. and Choi, Y. H. (2018) Spermidine protects against oxidative stress in inflammation models using macrophages and zebrafish. Biomol. Ther. (Seoul) 26, 146-156.

Karunarathne, W. A. H. M., Lee, K. T., Choi, Y. H., Jin, C. Y. and Kim, G. Y. (2020) Anthocyanins isolated from Hibiscus syriacus L. attenuate lipopolysaccharide-induced inflammation and endotoxic shock by inhibiting the TLR4/MD2-mediated NF-KB signaling pathway. Phytomedicine 76, 153237.

Kim, S. Y., Jin, C. Y., Kim, C. H., Yoo, Y. H., Choi, S. H., Kim, G. Y., Yoon, H. M., Park, H. T. and Choi, Y. H. (2019) Isorhamnetin alleviates lipopolysaccharide-induced inflammatory responses in BV2 microglia by inactivating NF- $\kappa B$, blocking the TLR4 pathway and reducing ROS generation. Int. J. Mol. Med. 43, 682-692.

Koopman, W. J., Nijtmans, L. G., Dieteren, C. E., Roestenberg, P.,
Valsecchi, F., Smeitink, J. A. and Willems, P. H. (2010) Mammalian mitochondrial complex I: biogenesis, regulation, and reactive oxygen species generation. Antioxid. Redox Signal. 12, 1431-1470.

Kowalska, M., Piekut, T., Prendecki, M., Sodel, A., Kozubski, W. and Dorszewska, J. (2020) Mitochondrial and nuclear DNA oxidative damage in physiological and pathological aging. DNA Cell Biol. 39, 1410-1420.

Kwon, J., Han, E., Bui, C. B., Shin, W., Lee, J., Lee, S., Choi, Y. B., Lee, A. H., Lee, K. H., Park, C., Obin, M. S., Park, S. K., Seo, Y. J., Oh, G. T., Lee, H. W. and Shin, J. (2012) Assurance of mitochondrial integrity and mammalian longevity by the p62-Keap1-Nrf2-Nqo1 cascade. EMBO Rep. 13, 150-156.

Lee, I. T. and Yang, C. M. (2012) Role of NADPH oxidase/ROS in pro-inflammatory mediators-induced airway and pulmonary diseases. Biochem. Pharmacol. 84, 581-590.

Liu, C., Zhu, P., Fujino, M., Isaka, Y., Ito, H., Takahashi, K., Nakajima, M., Tanaka, T., Zhuang, J. and Li, X. K. (2019) 5-aminolaevulinic acid (ALA), enhances heme oxygenase ( $\mathrm{HO})-1$ expression and attenuates tubulointerstitial fibrosis and renal apoptosis in chronic cyclosporine nephropathy. Biochem. Biophys. Res. Comm. 508, 583-589.

Liu, Z., Ren, Z., Zhang, J., Chuang, C. C., Kandaswamy, E., Zhou, T. and Zuo, L. (2018) Role of ROS and nutritional antioxidants in human diseases. Front. Physiol. 9, 477.

Loboda, A., Damulewicz, M., Pyza, E., Jozkowicz, A. and Dulak, J. (2016) Role of Nrf2/HO-1 system in development, oxidative stress response and diseases: an evolutionarily conserved mechanism. Cell. Mol. Life Sci. 73, 3221-3247.

Mills, E. L. and O'Neill, L. A. (2016) Reprogramming mitochondrial metabolism in macrophages as an anti-inflammatory signal. Eur. J. Immunol. 46, 13-21.

Murphy, M. P. (2009) How mitochondria produce reactive oxygen species. Biochem. J. 417, 1-13.

Nakano, Y., Kitagawa, T., Osada, Y., Tanaka, T., Nishizawa, S. and Yamamoto, J. (2019) 5-Aminolevulinic acid suppresses prostaglandin E2 production by murine macrophages and enhances macrophage cytotoxicity against glioma. World Neurosurg. 127, e669-e676.

Ollinger, R., Wang, H., Yamashita, K., Wegiel, B., Thomas, M., Margreiter, R. and Bach, F. H. (2007) Therapeutic applications of bilirubin and biliverdin in transplantation. Antioxid. Redox Signal. 9, 21752185.

Park, S., Kim, M., Hong, Y., Lee, H., Tran, Q., Kim, C., Kwon, S. H., Park, J., Park, J. and Kim, S. H. (2020) Myristoylated TMEM39AS41, a cell-permeable peptide, causes lung cancer cell death. Toxicol. Res. 36, 123-130.

Popa, C., Netea, M. G., van Riel, P. L., van der Meer, J. W. and Stalenhoef, A. F. (2007) The role of TNF-alpha in chronic inflammatory conditions, intermediary metabolism, and cardiovascular risk. J. Lipid Res. 48, 751-762.

Rodríguez-Ruiz, L., Lozano-Gil, J. M., Lachaud, C., Mesa-Del-Castillo, P., Cayuela, M. L., García-Moreno, D., Pérez-Oliva, A. B. and Mulero, V. (2020) Zebrafish models to study inflammasome-mediated regulation of hematopoiesis. Trends Immunol. 41, 1116-1127.

Saha, S., Buttari, B., Panieri, E., Profumo, E. and Saso, L. (2020) An overview of Nrf2 signaling pathway and its role in inflammation. Molecules 25, 5474.

Saini, R. and Singh, S. (2019) Inducible nitric oxide synthase: an asset to neutrophils. J. Leukoc. Biol. 105, 49-61.

Shi, J., Yu, J., Zhang, Y., Wu, L., Dong, S., Wu, L., Wu, L., Du, S., Zhang, Y. and Ma, D. (2019) PI3K/Akt pathway-mediated HO-1 induction regulates mitochondrial quality control and attenuates endotoxin-induced acute lung injury. Lab. Invest. 99, 1795-1809.

Singh, A., Kukreti, R., Saso, L. and Kukreti, S. (2019) Oxidative stress: a key modulator in neurodegenerative diseases. Molecules 24, 1583.

Skuratovskaia, D., Komar, A., Vulf, M. and Litvinova, L. (2020) Mitochondrial destiny in type 2 diabetes: the effects of oxidative stress on the dynamics and biogenesis of mitochondria. PeerJ 8, e9741.

Soufli, I., Toumi, R., Rafa, H. and Touil-Boukoffa, C. (2016) Overview of cytokines and nitric oxide involvement in immuno-pathogenesis of inflammatory bowel diseases. World J. Gastrointest. Pharmacol. Ther. 7, 353-360. 
Sugiyama, Y., Hiraiwa, Y., Hagiya, Y., Nakajima, M., Tanaka, T. and Ogura, S. I. (2018) 5-Aminolevulinic acid regulates the immune response in LPS-stimulated RAW 264.7 macrophages. BMC Immunol. 19, 41.

Uchida, A., Kidokoro, K., Sogawa, Y., Itano, S., Nagasu, H., Satoh, M., Sasaki, T. and Kashihara, N. (2019) 5-Aminolevulinic acid exerts renoprotective effect via Nrf2 activation in murine rhabdomyolysisinduced acute kidney injury. Nephrology (Carlton) 24, 28-38.

Utzeri, E. and Usai, P. (2017) Role of non-steroidal anti-inflammatory drugs on intestinal permeability and nonalcoholic fatty liver disease. World J. Gastroenterol. 23, 3954-3963.

Vanella, L., Barbagallo, I., Tibullo, D., Forte, S., Zappalà, A. and Li Volti, G. (2016) The non-canonical functions of the heme oxygenases. Oncotarget 7, 69075-69086.

Wang, T., He, C. and Yu, X. (2017) Pro-inflammatory cytokines: new potential therapeutic targets for obesity-related bone disor- ders. Curr. Drug Targets 18, 1664-1675.

Yao, C. and Narumiya, S. (2019) Prostaglandin-cytokine crosstalk in chronic inflammation. Br. J. Pharmacol. 176, 337-354.

Yu, W., Wang, X., Zhao, J., Liu, R., Liu, J., Wang, Z., Peng, J., Wu, H., Zhang, X., Long, Z., Kong, D., Li, W. and Hai, C. (2020) Stat2-Drp1 mediated mitochondrial mass increase is necessary for pro-inflammatory differentiation of macrophages. Redox Biol. 37, 101761.

Zhang, H., Cai, D. and Bai, X. (2020) Macrophages regulate the progression of osteoarthritis. Osteoarthritis Cartilage 28, 555-561.

Zhao, M., Zhu, P., Fujino, M., Nishio, Y., Chen, J., Ito, H., Takahashi, K., Nakajima, M., Tanaka, T., Zhao, L., Zhuang, J. and Li, X. K. (2016) 5-Aminolevulinic acid with sodium ferrous citrate induces autophagy and protects cardiomyocytes from hypoxia-induced cellular injury through MAPK-Nrf-2-HO-1 signaling cascade. Biochem. Biophys. Res. Commun. 479, 663-669. 